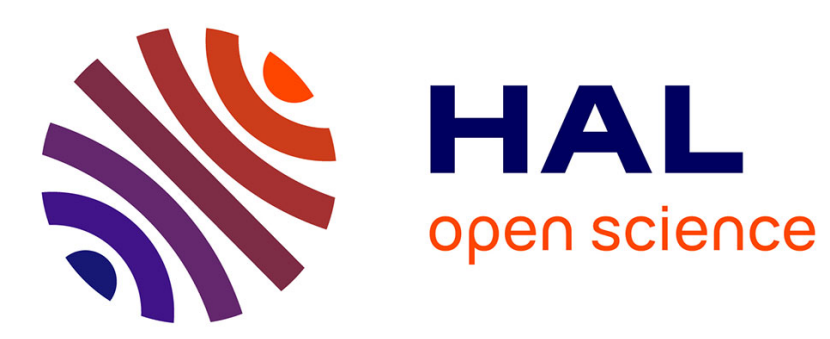

\title{
Impact of maintenance on replacement investment under technological improvement
}

Thi Phuong Khanh Nguyen, Thomas G. Yeung, Bruno Castanier

\section{To cite this version:}

Thi Phuong Khanh Nguyen, Thomas G. Yeung, Bruno Castanier. Impact of maintenance on replacement investment under technological improvement. ESREL 2011 Advances in Safety, Reliability and Risk Management, Sep 2011, France. pp.869-876. hal-00728079

\section{HAL Id: hal-00728079 \\ https://hal.science/hal-00728079}

Submitted on 5 Sep 2012

HAL is a multi-disciplinary open access archive for the deposit and dissemination of scientific research documents, whether they are published or not. The documents may come from teaching and research institutions in France or abroad, or from public or private research centers.
L'archive ouverte pluridisciplinaire HAL, est destinée au dépôt et à la diffusion de documents scientifiques de niveau recherche, publiés ou non, émanant des établissements d'enseignement et de recherche français ou étrangers, des laboratoires publics ou privés. 


\title{
Impact of maintenance on the replacement investment under technological improvement
}

\author{
T.P.K. Nguyen, T. G. Yeung \& B. Castanier \\ Ecole des Mines de Nantes, Nantes, France
}

\begin{abstract}
An unexplored important area in the equipment investment problem under technological improvement is the impact of maintenance policy. In fact, maintenance not only helps to maximize the profitability of the asset, but also prolong its economic life while waiting the apparition of better technology in the near future. Therefore, we propose a model that allows us to consider how replacement investment in a new or improved asset will be influenced by maintenance. The investment decisions are based on information about the profitability of the current asset and the technological environment. For the maintenance process, we also consider the dependency of its cost and efficiency on the deterioration state of asset that is represented by a profit parameter. We use a non-stationary Markov decision process to solve for the optimal investment/maintenance policy and illustrate the potential benefits of integrating maintenance policies in the investment strategy through different numerical analysis.
\end{abstract}

\section{INTRODUCTION}

The replacement investment decision is clearly a strategic objective of a company as it defines its future competitiveness and the potential large costs incurred. This decision must be based on the maximum available information in the company to ensure a favorable outcome. All relevant information for the replacement decision largely depends on the company context. However, we can summarize the motivations leading to an investment by the estimated performance (technical and economic) gap between the current system and competing technologies available on the market, taking into account budgetary constraints.

Research in the area of technology investment has taken many directions. In general, they can be classified in two aspects: economic/management science and operations research areas. In the former, the articles are based more on the modeling of the maintenance process through cost functions instead of the traditional failure indicators such as the degradation or failure rate models. One of the first articles dealing with this problem was published in 1976 (Elton \& Gruber, 1976). In this early study, the authors assume that the technology develops linearly over time and prove that the replacement policy at equal intervals is optimum. However, the linear model is too restrictive, not appropriate to simulate the flexible development of technology. On the other hand, a new model: geometric technological evolution is developed by (Natali \& Yatsenko. 2007, 2008a, b, 2009, Smith \& Torpong. 2003). They utilize the geometric model to form the cost functions depending on equipment vintage or on time. The uncertainty of technology breakthrough time is captured by (Nair. 1995). He presents a model in which the technological change is stochastic over time with a non-stationary appearing probability of new technology. Nevertheless, all above models do not tackle the high level of uncertainty in the cost and the associated revenues. This characteristic is represented by a few articles such as Bethuyne (2001), Huisman \& Kort (2004) and Mauer \& Ott (1995). They also use geometric Brownian motion to represent the profit flow (Huisman \& Kort 2004), or the cost (Mauer \& Ott 1995, Bethuyne 2001).

With these models, the managers can decide the best time for replacement investment of equipment under technological evolution but do not consider the maintenance strategies.

On the other side, in the operation research area, Borgonovo et al. (2000), Clavareau \& Labeau (2009a, b), Hopp \& Nair (1994), Nguyen et al. $(2010 \mathrm{a}, \mathrm{b})$ also examine the maintenance policy. However, because of the complexity of the system, they must simplify the technological evolution model. They consider a single new technology that has already appeared on the market with deterministic parameters (Clavareau \& Labeau 
$2009 \mathrm{a}, \mathrm{b})$ or a geometric sequence of technology evolution, represented by the exponential decrease of the failure rate over time (Borgonovo et al. 2000). In fact, this assumption is unreasonable because technical characteristics of equipments cannot always be changed over time. It changes only at the concurrent instant of a new technological generation. While Hopp \& Nair (1994) examine a single new technology, Nguyen et al. (2010a, b) consider a technological innovation sequence. Furthermore, all above articles focus on optimizing the maintenance-replacement policy instead of considering the impact of maintenance on the investment decision.

These reasons motivate us to provide an appropriate model to meet the operational and strategic requirements. This model is developed to examine how replacement investment policies will be influenced by the maintenance option. We consider the discretized problem where the time horizon is characterized by the estimated maximal apparition time of new technology as we assume there is only one technological breakthrough in the planning horizon. This technology breakthrough is modeled by a non-homogenous Poisson process and the effect of a new technology is measurable through the degradation characteristics as well as its stochastic acquisition cost function. We assume that a new technology should always have an increasing performance, but its purchase cost may either increase or decrease. We also consider that the stochastic profitability process of an asset is defined by both the technical performance of asset, and the uncertainty of the market. For maintenance processes, we consider the dependency of its cost and its efficiency on the deterioration state of asset that is characterized by profit parameter. A discrete time, non-stationary Markov decision process (MDP) is proposed to determine the optimal action plan. The impact of maintenance on the investment policy is analyzed by different numerical examples.

The remainder of this paper is structured as follows: In Section 2, we present our mathematical formulation model and its assumptions.. In Section 3 , the performance of our model is discussed through numerical examples. Finally, conclusions and future work are discussed in Section 4.

\section{MODEL AND ASSUMPTIONS}

\subsection{Problem Statement}

Consider a repairable asset that operates continuously and generates the profit process $g(t)$ defined by both the technical performance of the asset and the uncertainty of the market in which it performs. We assume that the technical performance is decreasing in the deterioration state of asset, so on average, the profitability is decreasing from $g_{0}{ }^{0}$ - profit generated by new asset of the same technology to 0 over time.

Let $\tau$, be the decision interval. We assume that a new technology can appear in this interval with non-decreasing probability $p_{t}$. The difference between the technological generations is modeled by an improvement factor in their profitability, their degradation characteristics and their acquisition cost function.

Let $\left(g, c_{1}, j\right)$ be the system state at the beginning of the $t^{\text {th }}$ decision epoch with $g$ - profit generated at this moment by the asset that belongs to technological generation $j(j=0)$ : the old technology; $j=1$ : the new technology) while the purchase price of available new technology is $c_{1}$. Note that when new technology is not yet available, its purchase cost $c_{1}=0$. In addition, as the purchase price of a new technology asset cannot be estimated exactly, its value is modeled by a stochastic process over time. After the moment of technological breakthrough, the purchase price of new technology is constant while the purchase price of old technology, $c_{0}$ is decreasing.

At beginning of decision epoch $t$, the possible actions are:

1) Do nothing $(D N)$ : The asset continues to operate until the next decision epoch and generates a profit process $g(t+u),(0 \leq u \leq \tau)$, given that the value observed at the beginning of epoch is: $g_{t}=g$. The estimated economic gain accrued by the asset of technological generation $j$ in this period is equal to $E_{t}\left[G_{t} \mid g_{t}=g\right]$.

2) Investment $(I)$ : We replace the asset by an available technology $h$ in the market $(j \leq \mathrm{h} \leq 1)$. The replacement time is also negligible. The cost of such a replacement is given by the difference between the purchase price of the new asset $c_{h}$ and the salvage value $b_{j}(g)$. After replacement, the system generates a profit $g_{0}{ }^{h}$. Note that the performance characteristic of a new technology asset can be estimated. This is realistic in the case where the technical parameters and specifications of future designs may be assumed reasonably well beforehand.

3) Maintenance $(M)$ : restores the asset to an improved state, so its profit generated $\left(g^{+}\right)$is higher than before the maintenance $(g)$. Therefore, the effectiveness of maintenance is characterized by $d$ :

$$
g^{+}=g+d\left(g_{0}^{j}-g\right) \text {. }
$$

Note that:

$d=0$ characterizes an ineffective repair and $d=$ 1 a perfect repair. Finally, the maintenance cost is an increasing function over the maintenance efficiency. This common assumption is consistent with reality. 
$c_{M}(g)=a+k\left(g_{0}^{j}-g\right) ; a, k$ are constant.

We assume that the maintenance time is negligible.

\subsection{System performance}

The system performance is presented by the profit process over time that has drift $\mu<0$ (because of the deterioration characteristic of the asset) and the volatility per unit time $\sigma$. To model this process, we use geometric Brownian motion (GBM) that is the most widely used model of profit/cost flow behavior in financial domain (Huisman \& Kort 2004, Mauer \& Ott 1995, Bethuyne 2001, Nishimura \& Ozaki. 2007). Let $g_{t}$ be profit generated at the beginning of decision period $t, W_{\tau}$ $\sim N(0, \tau)$, the profit at the beginning of next period is then:

$g_{t+1}=g_{t} \exp \left[\left(\mu_{j}-\frac{\sigma^{2}}{2}\right) \tau+\sigma W_{\tau}\right]$

The expected cumulative profit $G_{t}$ within a decision period $t$, based on information available of profit $g_{t}=g$ at the beginning of this period, with the discount factor per unit time $r$, is given by the conditional expectation on $g_{t}$.

$E_{j}\left[G_{t} \mid g_{t}\right]=E\left[g \int_{0}^{\tau} \exp \left[\left(\mu_{j}-r-\frac{\sigma^{2}}{2}\right)+\sigma W_{u}\right] d u\right]$

With corollary 2 (Section 2.4 .2 p.33) by (Yor. 2001); we can prove:

$E_{j}\left[G_{t} \mid g_{t}=g\right]=\frac{g}{\mu_{j}-r}\left(\exp \left[\left(\mu_{j}-r\right) \tau\right]-1\right)$

\subsection{Technological evolution}

We consider only one new technology that can appear in the future with increasing probability over time. This assumption is consistent with character of technological breakthrough in reality and is presented by articles (Hoop \& Nair. 1994, Nair. 1995).

$p_{t+1}=1-\delta \varepsilon^{t} ; \quad \delta, \varepsilon \in(0,1)$

The $\delta$ factor reflects the non-appearance probability of new technology at the next decision epoch. Factor $\varepsilon$ characterizes the increasing rate of the appearance probability of new technology over time.

Technological innovation is characterized by an improvement on the initial profit (the profit is generated at moment of installation of the new asset): $g_{0}{ }^{0}<g_{0}{ }^{1}$ with drift: $\mu_{0}<\mu_{1}<0$. Due to the uncertainty of the apparition time of new technology uncertain and the volatility of the forecast increasing over time, we use geometric Brownian motion to model these characteristics. The purchase price of new technology $c_{1, u}$ at time $u$ is described as following:

$c_{1, u}=c_{1,0} \exp \left[\left(\mu_{c}-\frac{\sigma_{c}^{2}}{2}\right) u+\sigma_{c} W_{u}\right]$

where $c_{1, u}$ is initial estimated value of the new technology purchase price $\left(c_{1, u}>c_{0}\right)$. Under the risk neutral measure, we have $\mu$.

Finally, the salvage value of the asset at decision epoch $t$ depends on its acquired profit at $t$ and $j^{\text {th }}$ technological generation:

$b_{j}(g)=v+h_{j} g$

$v$ is defined as the 'junk value'; $v$ and $h_{j}$ are constant.

\subsection{Model formulation}

In this paper, we use a non-stationary MDP formulation to find the optimal maintenancereplacement policy to maximize the expected discounted value-to-go over the finite horizon time denoted by $V^{\pi}\left(q, c_{1}, j\right)$.

Let $V_{t}\left(q, c_{1}, j\right)$. denote the maximum expected discounted value from the decision epoch $t$ to the last epoch $N$. Then, $V_{1}\left(g, c_{1}, j\right)=V^{\pi}\left(g, c_{1}, j\right)$.

$$
\begin{gathered}
V_{t}\left(g, c_{1}, j\right)= \\
\max \left\{D N_{t}\left(g, c_{1}, j\right), I_{t}\left(g, c_{1}, j\right), M_{t}\left(g, c_{1}, j\right)\right\}
\end{gathered}
$$

where $D N_{t}, I_{t}, M_{t}$ are the respective possible actions to do nothing, invest, and maintain at decision epoch $t$. Therefore, the complete MDP formulation is given by:

$$
\begin{aligned}
& D N_{t}\left(g, c_{1}, j\right)= \\
& E_{j}\left[G_{t} \mid g_{t}=g\right]+ \\
& e^{-r \tau}\left[\sum_{\forall g^{\prime}} P_{j}\left(g^{\prime} \mid g\right) V_{t+1}\left(g^{\prime}, c_{1}, j\right)+\right. \\
& p_{t+1}\left[\sum_{\forall c_{1}} p_{t+1, c_{1}} \sum_{\forall g^{\prime}} P_{j}\left(g^{\prime} \mid g\right) V_{t+1}\left(g^{\prime}, c_{1}, j\right)-\right. \\
& \left.\left.\sum_{\forall g^{\prime}} P_{j}\left(g^{\prime} \mid g\right) V_{t+1}\left(g^{\prime}, c_{1}, j\right)\right] 1_{\left\{c_{1}=0\right\}}\right] \\
& I_{t}^{h}\left(g, c_{1}, j\right)=-c_{h}+b_{j}(g)+D N_{t}\left(g_{0}^{h}, c_{1}, h\right) \\
& \left(\begin{array}{rr}
j \leq h \leq 1 ; c_{0}=c & \text { if } c_{1}>0 \\
h=0 ; c_{0}=c^{\prime} & \text { if } c_{1}=0
\end{array}\right) \text { with } c^{\prime}<c \\
& M_{t}\left(g, c_{1}, j\right)=-c_{M}(g)+D N_{t}\left(g^{+}, c_{1}, j\right)
\end{aligned}
$$

Where: 
_ $P_{j}\left(g^{\prime} \mid g\right)$ : probability that the system generates a profit $g$ ' at beginning of period $t+1$ given that the profit generated at the beginning of period $t$ is $g$. - $p_{t+1}$ : apparition probability of new technology on next period.

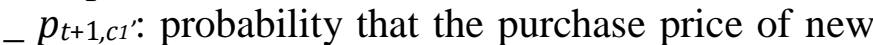
technology is $c_{1}{ }^{\prime}$ on next period, given at $t, c_{1}=0$.

\subsection{Transition probabilities}

Trigeorgis (1991) proposes a log-transformed binomial method to discretize the geometric Brownian motion. This method can be seen as a quality improvement of the binomial approximation but it is developed for valuing pricing option under risk neutrality assumption (the drift of GBM is small). In our problem, the drift of GBM that models the profit process is large because of deterioration characteristic of the asset. Therefore, we propose a method based on the theoretical design of Trigeorgis (1991) with a variation in step changes. form:

Recall that the profit process at time $u$ has the

$g_{u}=g_{0}^{j} \exp \left[\left(\mu_{j}-\frac{\sigma^{2}}{2}\right) \tau+\sigma W_{\tau}\right] ; W_{u} \sim N(0, u)$

In any differential time interval, $d u, Y=\log \left(g_{u}\right)$ follows an arithmetic Brownian motion. The increments, $d Y$, are independent, identical and normally distributed with mean and variance:

$E(d Y)=\left(\mu_{j}-\frac{\sigma^{2}}{2}\right) d u ; \quad \operatorname{Var}(d Y)=\sigma^{2} d u$

We approximate the continuous process above by subdividing the planning horizon $T$, into $N$ decision epochs of length $\tau$. Thus, $d u$ can be approximated by $\tau$. Within each discrete subinterval $\tau, Y$ follows a Markov random walk moving up by an amount $\Delta Y=E\left(d Y_{\mathrm{in \tau}}\right)+H$ with probability $P$ or down by the amount $\Delta Y=E\left(d Y_{\text {int }}\right)-H$ with probability $1-P$. The mean and variance of this discrete-time Markov process are:

$$
\begin{aligned}
E(\Delta Y)=P[E( & \left.\left(d Y_{i n \tau}\right)+H\right] \\
& +(1-P)\left[E\left(d Y_{i n \tau}\right)-H\right]
\end{aligned}
$$

$\operatorname{Var}(\Delta Y)=E\left[(\Delta Y-E(\Delta Y))^{2}\right]$

For the discrete-time process $t$ be consistent with the continuous diffusion process, their corresponding means and variances should be equal. So, from (12) and (13), we have:

$P=0.5$ and $H=\sigma \sqrt{\tau}$;
Given $g$ profit generated at the beginning of decision epoch $t$ and technology $j$. We have:

$P_{j}\left(g^{\prime} \mid g\right)=\left[\begin{array}{c}0.5 \text { with } g^{\prime}=g \exp [E(\Delta Y)+H] \\ \text { or } g^{\prime}=g \exp [E(\Delta Y)-H] \\ 0 \quad \text { others values }\end{array}\right.$

$E(d Y)=\left(\mu_{j}-\frac{\sigma^{2}}{2}\right) \tau$

To calculate the probability $p_{t+1, c 1^{\prime}}$ of the new technology's purchase price $c_{1}^{\prime}$ at $t+1$, given at $t$, $c_{1}=0$, we utilize the same method to discretize the pricing continue process. From (6), let $Y c=\log c_{1, u}$ so $Y c$ follows the process below:

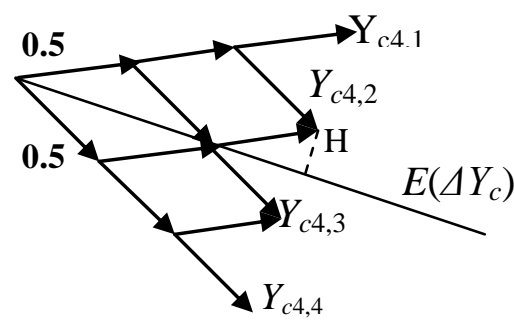

$\begin{array}{llllll}1 & 2 & 3 & 4 & \ldots & \mathrm{T}\end{array}$

Figure 1. The binomial tree - Discrete time model of geometric Brownian model.

At decision epoch $t$, the node value $Y_{t, m}$ of our binomial tree are given by the formula below:

$Y c_{1,1}=0 ; \quad H_{c}=\sigma_{c}{ }^{2} \tau, m$ : discrete state of $Y c$ $Y c_{t, 1}=Y c_{t-1,1}+H_{c}+\left(r-\frac{1}{2} \sigma_{c}^{2}\right) \tau ; 2 \leq t \leq \mathrm{T} ;$

$Y c_{t, m}=Y c_{t, 1}+2 H(m-1) ; \quad m \leq t$

The probability $p_{t, c_{1}}$ is calculated by:

$p_{t, c_{1}{ }^{\prime}}=P\left(c_{1, t}=c_{1}{ }^{\prime}\right)=P\left(Y_{c_{t, m}}\right)$;

$\forall c_{1}^{\prime}: c_{1}^{\prime}=c_{1,0} \exp \left[Y_{c_{t, m}}\right] ; \forall t: 2 \leq t \leq T$;

$\forall m: 1 \leq m \leq t$

$P\left(Y c_{t, m}\right)=P\left(Y c_{t-1, m-1}\right) 0.5+P\left(Y c_{t-1, m}\right) 0.5$;

$P\left(Y c_{2,1}\right)=0.5 ; \quad P\left(Y c_{2,2}\right)=0.5$

\section{NUMERICAL EXAMPLES}

In this section, we present numerical examples to illustrate the performance of our model and the impact of maintenance on the replacement investment decision. We consider days as the time unit and $\tau=30$ as decision period, thus each decision epoch equal one month. We also assume that the new technology will appear any time between from next decision epoch $(t=2)$ until $(t=$ 25 ), so the planning horizon is set at $T=25$. The 
input parameters for Example 1 are given in Table 1.

Table 1. The input parameters for the Example 1

\begin{tabular}{|c|c|c|c|c|c|}
\hline Discount factor & $r$ & $\delta$ & $\varepsilon$ & & \\
\hline Apparition prob & $3.10^{-4}$ & 0.9 & 0.9 & & \\
\hline Purchase price & C & $c^{\prime}$ & $c_{1,0}$ & $\sigma_{c}$ & \\
\hline & 330 & 300 & 495 & $5.2 .10^{-3}$ & \\
\hline Profit & $\frac{g_{0}^{0}}{10}$ & $\begin{array}{r}g_{0}^{1} \\
10.5 \\
\end{array}$ & $\begin{array}{l}\mu_{0} \\
3.10^{-3}\end{array}$ & $\begin{array}{c}\mu_{0} \\
2.7 .10^{-3}\end{array}$ & $\begin{array}{l}\sigma \\
6.3 .10^{-3}\end{array}$ \\
\hline Maintenance & $d$ & $a$ & $k$ & $v$ & $h_{0} \quad h_{1}$ \\
\hline Salvage value & $\overline{0.6}$ & 40 & 7 & 5 & $10 \quad 12$ \\
\hline
\end{tabular}

The optimal policy for the first four months of Example 1 in cases $j=0$ (i.e., old technology is utilized) is given in Table 2. With input parameters given in Table 1, the mean appearance time of new technology is 4.91 months and the mean first maintenance time is 3.34 months. The optimal investment strategy prescribes to replace the new technology when it becomes available on market $\left(c_{1} \neq 0\right)$.

Table 2. The optimal policy for the first four months in Example 1

\begin{tabular}{|c|c|c|c|c|}
\hline$t$ & $c_{1}$ & $\begin{array}{l}\text { Do Nothing } \\
{\left[\begin{array}{ll}g_{1} & \left.g_{2}\right)\end{array}\right.}\end{array}$ & $\begin{array}{l}\text { Maintenance } \\
{\left[g_{2}, g_{3}\right)}\end{array}$ & $\begin{array}{l}\text { Investment } \\
{\left[g_{3}, g_{4}\right]}\end{array}$ \\
\hline 1 & 0 & {$[10,8.65)$} & {$[8.65,0.85)$} & {$[0.85,0]$} \\
\hline \multirow[t]{3}{*}{2} & 0 & {$[10,8.55)$} & {$[8.55,0.55)$} & {$[0.55,0]$} \\
\hline & 514 & {$[10,8.55)$} & & {$[8.55,0]$} \\
\hline & 485 & {$[10,8.55)$} & & {$[8.55,0]$} \\
\hline \multirow[t]{6}{*}{3} & 0 & {$[10,8.55)$} & {$[8.55,0.25)$} & {$[0.25,0]$} \\
\hline & 533 & {$[10,8.55)$} & & {$[8.55,0]$} \\
\hline & 514 & {$[10,8.55)$} & & {$[8.55,0]$} \\
\hline & 503 & {$[10,8.55)$} & & {$[8.55,0]$} \\
\hline & 485 & {$[10,8.55)$} & & {$[8.55,0]$} \\
\hline & 476 & {$[10,8.55)$} & & {$[8.55,0]$} \\
\hline \multirow[t]{10}{*}{4} & 0 & {$[10,8.55)$} & {$[8.55,0.25)$} & {$[0.25,0]$} \\
\hline & 553 & {$[10,8.75)$} & {$[8.75,7.55)$} & {$[7.55,0]$} \\
\hline & 533 & {$[10,8.75)$} & {$[8.75,8.45)$} & {$[8.45,0]$} \\
\hline & 522 & {$[10,8.55)$} & & {$[8.55,0]$} \\
\hline & 514 & {$[10,8.55)$} & & {$[8.55,0]$} \\
\hline & 503 & {$[10,8.55)$} & & {$[8.55,0]$} \\
\hline & 493 & {$[10,8.55)$} & & {$[8.55,0]$} \\
\hline & 485 & {$[10,8.55)$} & & {$[8.55,0]$} \\
\hline & 476 & {$[10,8.55)$} & & {$[8.55,0]$} \\
\hline & 466 & {$[10,8.55)$} & & {$[8.55,0]$} \\
\hline
\end{tabular}

For each decision epoch $t$, with utilized technology $j=0$, the decision matrix defines the optimal decision according to the current profit $g$ : Do nothing if $g \in\left[g_{1}, g_{2}\right)$, maintain if $g \in\left[g_{2}, g_{3}\right]$ and invest to replace by the same or the new technology if $g \in\left[g_{3}, g_{4}\right]$.

We find that in the case of no obsolescence (i.e., $c_{1}=0$ as a new technology has not appeared), the firms tend to wait for new technology; the investment in the same technology is made only at the low profit levels. This replacement threshold $\left(g_{3}\right)$ is non-increasing through decision epochs $(t=$ $1,2,3,4)$ because the appearance probability is increasing over time. The maintenance action demonstrates its dominance because it not only helps to maximize the profitability of the available asset, but also prolongs the economic life of the asset by waiting the appearance of better technology in the near future. In fact, as illustrated in Figure 2, we find that the maintenance area in the non-obsolescence case of Example 1 is larger than the case where we do not consider the possibility of new technology.

Furthermore, the impact of maintenance on the investment policy is strengthened by an increased appearance probability of new technology i.e., maintenance allows us to reduce the replacement threshold. The smaller the average appearance time of new technology, the more important this effect is.
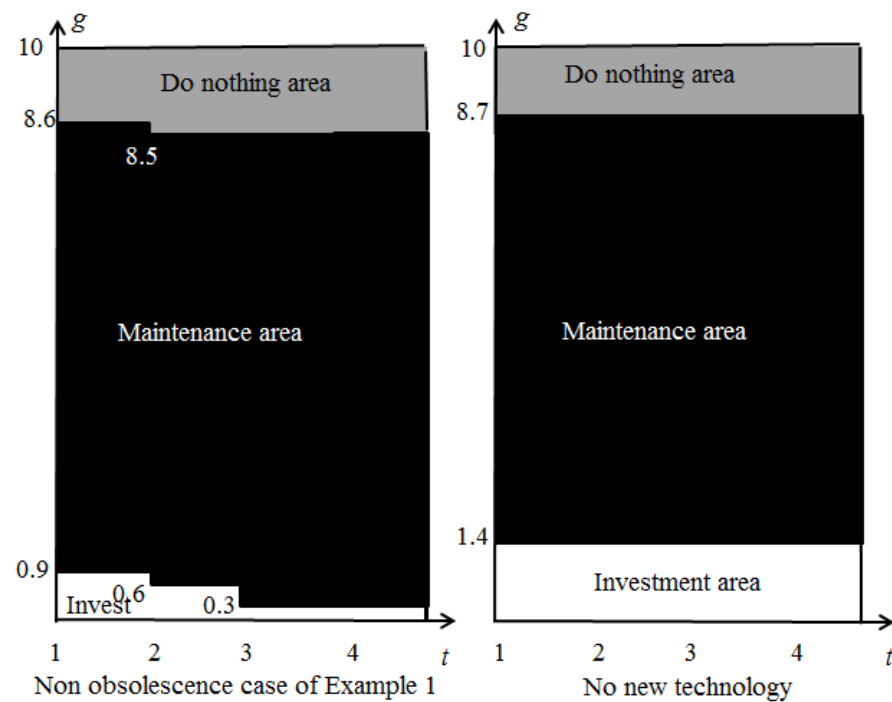

Figure 2. The optimal policy for the first four months in Example 1 (non-obsolescence case) and in the case where new technology is not considered

To illustrate this property, we consider the case where new technology may appear with the same probability at the second period: $p_{2}=0.1$, but their increase rates over time are different. We utilize the average appearance times (AAT) of new technology 2.98; 3.67; 4.91 (same as Example 1); $5.77 ; 10.35$ as alternatives in our experiment.

Consider Figure 3, the replacement thresholds are $g=1.05,0.85,0.75,0.75$ through decision epochs $t=1,2,3,4$ when the AAT of new technology is 5.77. These thresholds are lowered to $g=0.35,0,0,0$ when the new technology will appear at $t=2.98$ in average. Note that when the investment threshold is $g=0$, replacement by the same technology is not allowed. On the other hand, we find that in the case where the AAT is 10.35 , as the appearance probability is small and its increase rate is slow, the replacement threshold is non- 
decreasing through four decision epochs $(g=0.95$, $0.95,1.05,1.05)$, i.e., waiting for new technology is not encouraged.

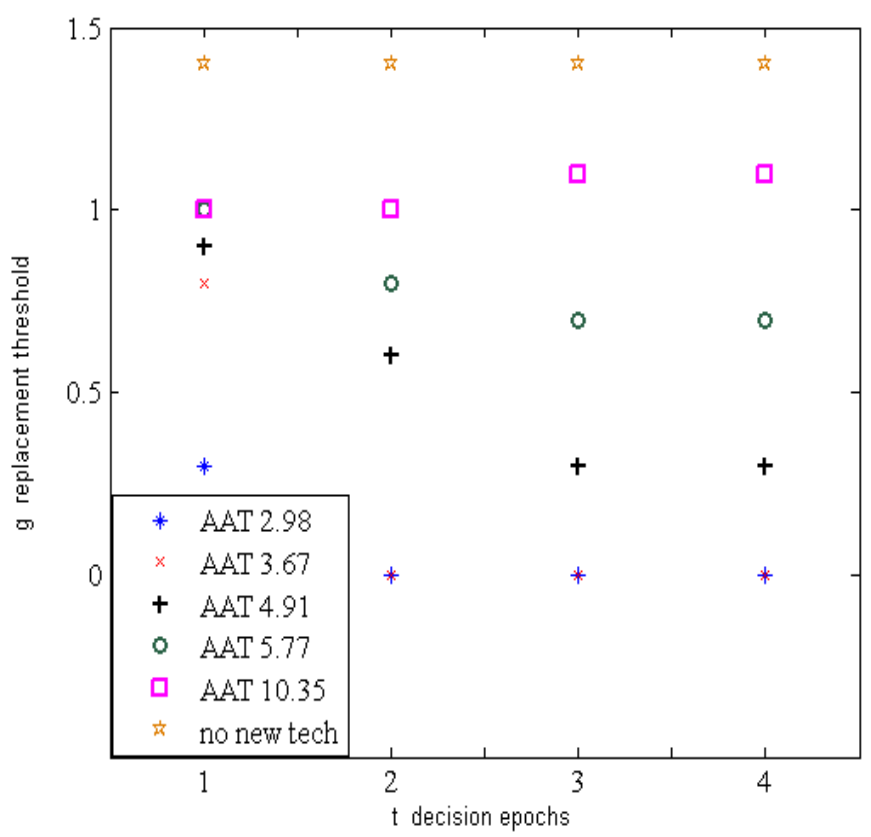

Figure 3. Impact of the average appearance time (AAT) of new technology on replacement threshold in nonobsolescence case.

In the obsolescence case, $\left(c_{1} \neq 0\right)$, maintenance no longer demonstrates its dominance. The firm tends to invest in new technology if it is available on the market. Consider in Table 1, the replacement threshold $g=8.55$ in decision epochs $t=2,3$ with its estimated purchase price level $476 \leq c_{1} \leq 533$. The maintenance action is selected only from the fourth decision epochs, $t=4$ when the purchase price is at higher level $c_{1}=553$ or $c_{1}=533$. However, in comparison with the case where no maintenance is considered (we have only two choices: 1) do nothing or 2) invest), we find that the impact of maintenance on the investment policy is non-monotone over time and depends on the purchase price level. Consider that the new technology appears at $t=4$ with the high purchase price $c_{1}=553$ or with the low purchase price $c_{1}=$ 466. As illustrated in Figure 4, in the case without maintenance, the investment threshold is 6.95 through all decision epochs. In the case of the low purchase price, the consideration of maintenance motivates us to invest in new technology because it allows us to maximize the profitability of the better technology characterized by the initial profit and the drift of profit flow. Contrarily, in the case of high purchase price, maintenance allows us to weigh the benefits of utilizing the available asset and the revenues of investment in new technology.

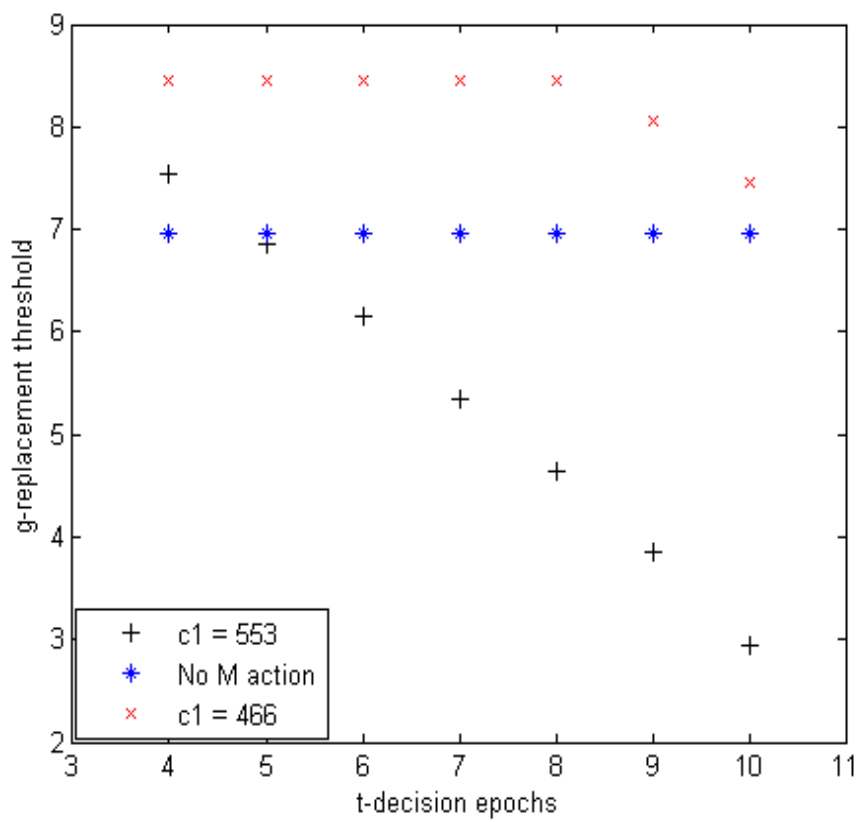

Figure 4. Impact of maintenance action on the investment threshold in obsolescence case.

Next we consider the effect of maintenance efficiency on the investment strategy. Recall this efficiency is represented by the factor $d, 0 \leq d \leq 1$. As illustrated in Table 3, the higher the factor $d$ is, the larger the maintenance area is, because the maintenance efficiency is improved.

In the non-obsolescence case, the impact of the maintenance efficiency on replacement threshold is monotone: the higher the maintenance efficiency is, the lower the replacement threshold is. The increased maintenance efficiency is beneficial to prolong economic life of the current asset while waiting new technology. This tendency is shown clearly by Figure 5. Consider for example that investment in new technology is not optimal through the first four decision epochs if $d=0.8$, and if $d=0.4$, the replacement threshold is raised at $g=$ $6.05,5.85,5.65,5.55$.

Table 3. The replacement area for the first four decision epochs with $d=0.8 ; 0.6 ; 0.4$.

\begin{tabular}{cccccc}
\hline$i$ & $c_{1}$ & $d=0.8$ & $d=0.6$ & $d=0.4$ \\
\hline 1 & 0 & {$[8.75$,} & $0)$ & {$[8.65,0.85)$} & {$[8.35,6.05)$} \\
2 & 0 & {$[8.75$,} & $0)$ & {$[8.55,0.55)$} & {$[8.25,5.85)$} \\
& 514 & & & & \\
& 485 & & & & \\
3 & 0 & {$[8.75$,} & $0)$ & {$[8.55,0.25)$} & {$[8.05,5.65)$} \\
& 533 & {$[8.85,5.75)$} & & \\
& 514 & {$[8.85,8.25)$} & & \\
& 503 & & & \\
& 485 & & & \\
& 476 & & &
\end{tabular}




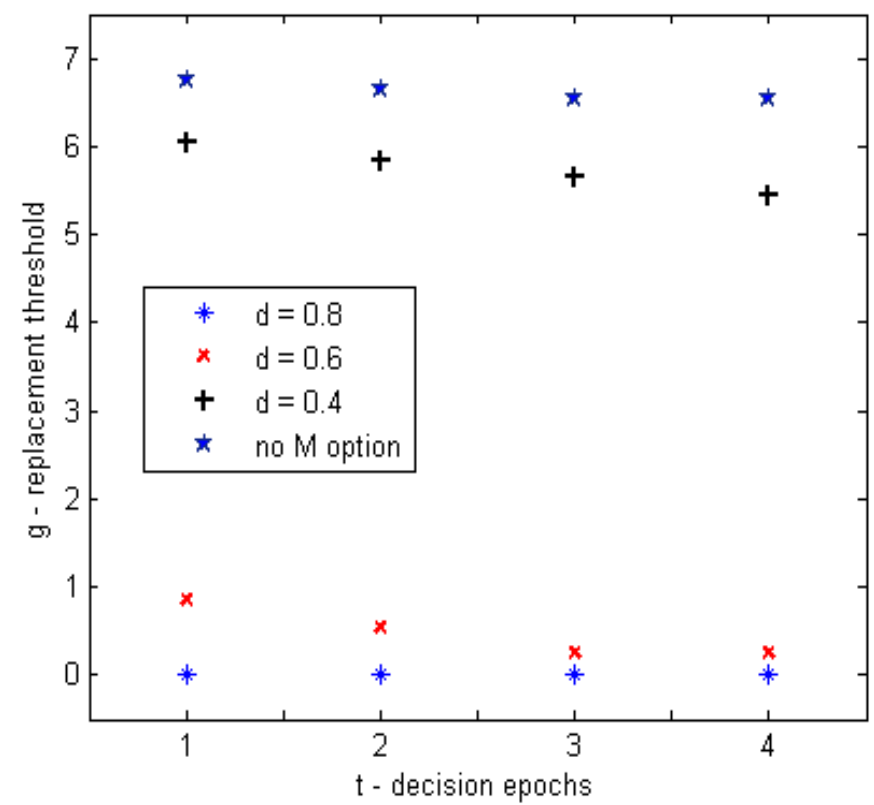

Figure 5. The replacement threshold in the case nonobsolescence for the first four decision epochs.

The case where the obsolete problem appears is more complex. The impact of maintenance efficiency on investment threshold is non-monotone and depends strictly on purchase price levels. For example, new technology appears at $t=2$ in two situations with $c_{1}=514$ or 485 . The optimal policy for the first five decision epochs prescribes the same investment threshold for two purchase price levels $c_{1}=514,485$ in the case where we do not consider maintenance option or the maintenance efficiency is not important: $d=0.4,0.6$. With efficient maintenance actions $(d=0.8)$, the investment policy for these price levels is rather different. As illustrated in Figure 6, we find that when the maintenance efficiency is improved (in the case: $d=0.4,0.6$ ) we tend to replace soon because the implementation of the optimal maintenance policy on new technology will obtain more profit than the current asset. However if the maintenance efficiency is really important, and the purchase price is at a high level, the firms weigh the benefits of utilizing the available asset and the revenues of investment in new technology, especially in the limited planning horizon. Hence, the investment threshold may be lowered.

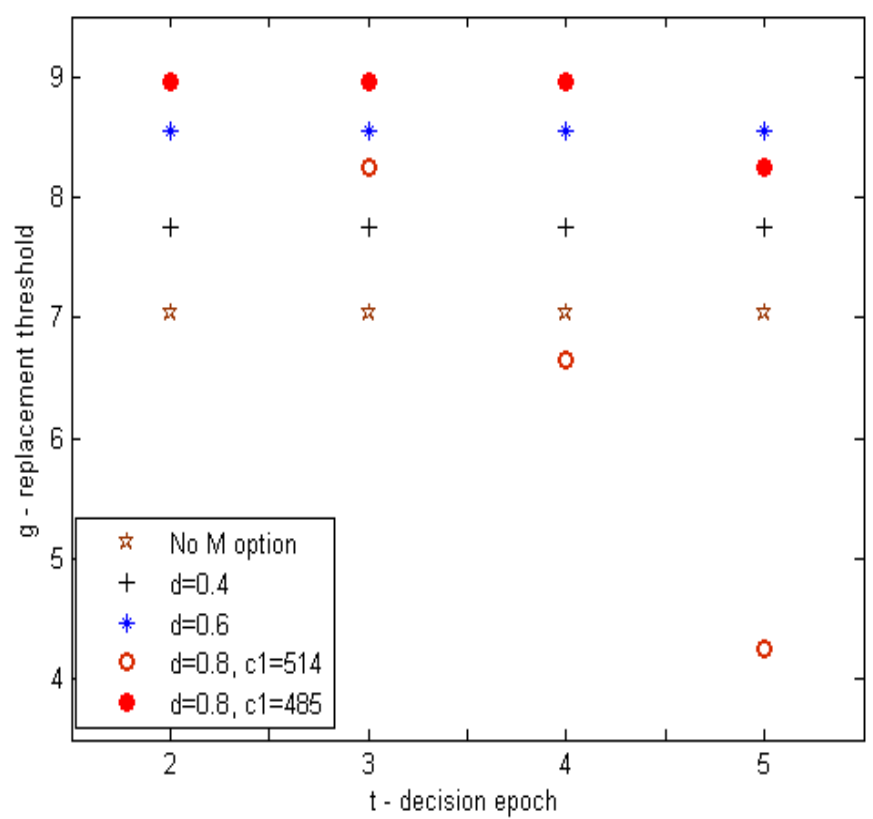

Figure 6. The replacement threshold in the case obsolescence assuming new technology appears at $\mathrm{t}=2$ with $\mathrm{c}_{1}=514$ or 485 .

\section{CONCLUSION}

In this paper, we proposed a model that allows managers to plan replacement investment under technological improvement in an operational context: considering the impact of maintenance on the technological investment decision. We also take into account market uncertainty by modeling profit flow and new technology purchase price as stochastic processes.

Through our numerical examples we have shown the importance of maintenance when considering the investment strategy in new technology. In fact, when the technological breakthrough has not appeared yet, it is obvious that maintenance allows us to extend the profitability of the current asset while waiting new technology. In the obsolescence case, the replacement option by new technology is motivated at lower purchase prices. Contrarily, with a high purchase price of new technology, the maintenance is beneficial as the alternative to replacement investment, especially when the maintenance efficiency is high.

The proposed assumptions on planning horizon can be seen as a limitation of our model. In future research we will consider optimizing the time horizon. Furthermore, the representation of the stochastic property of profit flow and purchase cost generates an immense state space, that causes difficulty in implementation. A more efficient algorithm for optimizing the maintenance/ investment policy should also be developed. 


\section{REFERENCES}

Bethuyne, G. 2002. The timing of technology Adoption by a cost-minimizing firm. Journal of Economics 76: 123-154.

Borgonovo, E; Marseguerra, M \& Zio, E. 2000. A Monte Carlo methodological approach to plant availability modeling with maintenance, aging and obsolescence. Reliability Engineering and System Safety 67: 61-73.

Clavareau, J \& Labeau, P.E. 2009a. A Petri net-based modeling of replacement strategies under technological obsolescence. Reliability Engineering and System Safety 94: 357- 369

Clavareau, J \& Labeau, P.E. 2009b. Maintenance and replacement policies under technological obsolescence. Reliability Engineering and System Safety 94: 370-381.

Dogramaci, A \& Fraiman, N.M. 2004. Replacement decisions with maintenance under uncertainty: an imbedded optimal control Model. Operations Research 52: 785-794.

Elton, E.J \& Gruber, M.J. 1976. On the optimality of Equal life policy for equipment subject to technological improvement. Operational Research Quarterly 27: 93-99.

Hopp, W.J \& Nair, S.K. 1994. Markovian deterioration and technological change. IIE Transactions 26: 74

Huisman, K.J.M \& Kort, P.M. 2003. Strategic technology adoption taking into account future technological improvement: A real options approach. European Journal of Operational Research 159: 705-728.

Mauer, D.C \& Ott, S.H. 1995. Investment under uncertainty: The case of replacement investment decisions. The journal of financial and quantitative analysis 30: 581-605.

Mercier, S. 2008. Optimal replacement policy for obsolete components with general failure rates submitted to obsolescence. Applied Stochastic Models in Business and Industry 24: 221-235.

Nair, S.K. 1995. Modeling strategic investment decisions under sequential technological change. Management Science 41: 282-297.

Natali, H \& Yatsenko, Y. 2007. Optimal equipment replacement without paradoxes: A continous analysis. Operations Research Letters 35: 245-250.

Natali, H \& Yatsenko, Y. 2008b. The dynamics of asset lifetime under technological change. Operations Research Letter 36: 565-568.

Natali, H \& Yatsenko, Y. 2008a. Properties of optimal service life under technological change. Int. J. Production Economics 114: 230-238.

Natali, H \& Yatsenko, Y. 2009. Integral equation of optimal replacement: Analysis and algorithms. Applied Mathematical Modeling 33: 237-274.

Nguyen, T.P.K, Yeung, G.T \& Castanier, B. 2010. Optimal maintenance and replacement decisions under technological change. International conference ESREL 2010 - Reability, Risk and Safety 2010: 1430 - 1437.

Nguyen, T.P.K, Yeung, G.T \& Castanier, B. 2010. Optimal Maintenance and Replacement Decisions under Technological Change with Consideration of Spare Parts Inventories. Technical paper. 11/05/AUTO.

Nishimura, K.G \& Ozaki, H. 2007. Irreversible investment and Knightian uncertainty. Journal of Economic Theory 136: 668-694.

Smith, R.L. \& Torpong. C. 2003. A paradox in equipment replacement under technological improvement. Operations Research Letters 31: 77-82.

Trigeorgis, L. 1991. A Log-transformed binomial numerical analysis method for valuing complex multi-option investments. The journal of financial and quantitative analysis 26: 309 - 326.

Yor, M. 2001: Exponential functional of Brownian motion and related process. Springer Finance. ISBN 3-54065943-9. 